\title{
A novel scoring index by Doppler echocardiography for predicting severe pulmonary hypertension due to chronic lung diseases: a cross-sectional diagnostic accuracy study
}

\author{
This article was published in the following Dove Press journal: \\ International Journal of COPD \\ 14 June 2017 \\ Number of times this article has been viewed
}

\author{
Rong Jiang' \\ Cheng Wu $\mathbf{W}^{2}$ \\ Bigyan Pudasaini' \\ Lan Wang' \\ Qin-Hua Zhao' \\ Rui Zhang' \\ Wen-Hui Wu' \\ Ping Yuan' \\ Zhi-Cheng Jing' \\ Jin-Ming Liu' \\ 'Department of Cardio-Pulmonary \\ Circulation, Shanghai Pulmonary \\ Hospital, Tongji University School \\ of Medicine, ${ }^{2}$ Department of Health \\ Statistics, Second Military Medical \\ University, Shanghai, People's \\ Republic of China
}

Background: Severe pulmonary hypertension ( $\mathrm{PH}$ ) resulting from a chronic lung disease (CLD) (severe CLD-PH) requires more aggressive treatment due to its increased mortality compared with mild PH. Therefore, we developed a Doppler echocardiography scoring index (ESI) to predict severe CLD-PH.

Methods: A derivation cohort of 107 patients with CLD who underwent echocardiography was classified into two groups, the normal/mild PH group and the severe PH group, based on the right heart catheterization. Meanwhile, we designed the ESI by multivariate logistic regression to validate the predicted outcomes. The ESI was calculated using the following formula: $\mathrm{ESI}=\mathrm{ESI}_{\mathrm{RVEDTD}}+\mathrm{ESI}_{\mathrm{PASP}}+\mathrm{ESI}_{\mathrm{PAd}}-\mathrm{ESI}_{\mathrm{TAPSE}}$. Additionally, the ESI was weighted by +2 points for right ventricular end-diastolic transverse dimension $\geq 3.8 \mathrm{~cm}$ or pulmonary artery diameter $\geq 2.7 \mathrm{~cm},+3$ points for systolic pulmonary artery pressure (PASP) $\geq 61 \mathrm{mmHg}$, and -3 points for tricuspid annular plane systolic excursion $\geq 1.65 \mathrm{~cm}$.

Results: In the derivation cohort, PASP $\geq 61 \mathrm{mmHg}$ estimated by echocardiography exhibited $80.4 \%$ sensitivity and $84.3 \%$ specificity with area under receiver-operating characteristic curve of 0.823 (95\% CI: 0.797-0.942, $P<0.0001$ ). Compared with PASP, ESI $\geq 1.0$ exhibited $91.1 \%$ sensitivity and $80.4 \%$ specificity, resulting in a net improvement in model performance with a change in the $c$-statistic from 0.823 to 0.937 and an integrated discrimination improvement of $11.3 \%$ (95\% CI: $4.5 \%-18.2 \%, P=0.001)$. The ESI was applied to the validation cohort, resulting in $84.2 \%$ sensitivity and $81.3 \%$ specificity with $82.9 \%$ accuracy.

Conclusion: The ESI showed high capacity for predicting severe CLD-PH, further implying the value of noninvasive examinations in clinic.

Keywords: pulmonary hypertension, echocardiography, hemodynamics, right heart catheterization, chronic lung disease

\section{Introduction}

Pulmonary hypertension (PH) is a common complication of a chronic lung disease (CLD) and is associated with increased mortality. ${ }^{1,2} \mathrm{PH}$ often progresses to right heart failure (RHF), with initial compensatory right ventricle (RV) hypertrophy becoming overwhelmed by increasing pulmonary artery pressure (PAP). According to the updated conference consensus, ${ }^{2,3}$ CLD is classified into three groups: without PH (mean PAP [mPAP] $<25 \mathrm{mmHg}$ ), with PH (mPAP $\geq 25 \mathrm{mmHg}$ ), and with severe $\mathrm{PH}(\mathrm{mPAP} \geq 35 \mathrm{mmHg}$ or $25 \mathrm{mmHg}<\mathrm{mPAP}<35 \mathrm{mmHg}$ with cardiac index $<2.0 \mathrm{~L} / \mathrm{min} / \mathrm{m}^{2}$ or pulmonary vascular resistance [PVR] $>6$ Wood units).
Correspondence: Jin-Ming Liu;

Zhi-Cheng Jing

Department of Cardio-Pulmonary

Circulation, Shanghai Pulmonary Hospital, Tongji University School of

Medicine, 507 Zhengmin Road, Yangpu

District, Shanghai 200433, People's

Republic of China

Email jinmingliu20I3@I26.com;

jingzhicheng@vip.163.com 
However, the severe PH group includes only a minority of patients with CLD who are suspected of having extensive general vascular remodeling accompanying the parenchymal disease that develops independently from pulmonary functional impairment and who have a poor prognosis. The detection of severe $\mathrm{PH}$ is important because it can provide the prognostic information to warrant more aggressive respiratory support and interventional cardiovascular procedures.

Right heart catheterization (RHC) is the gold standard for the diagnosis of severe $\mathrm{PH}$ because this method provides the hemodynamic information that defines this disease. Nevertheless, RHC is not routinely and repeatedly performed at initial diagnosis of $\mathrm{PH}$ and follow-up, especially in the People's Republic of China, where performance of RHC is limited by its invasiveness and high expenses. As a PHscreening tool, systolic PAP (PASP) can be estimated by measuring the peak tricuspid regurgitation velocity (TRV) on echocardiography, which continues to be recommended for early screening and as an assessment tool in patients with pulmonary arterial hypertension (PAH). However, in spite of its widespread use, the accuracy and reproducibility of echocardiography in predicting PASP have recently been questioned. ${ }^{4-9}$

The recently updated European Society of Cardiology (ESC) and European Respiratory Society guidelines on $\mathrm{PH}$ recommend testing for additional $\mathrm{PH}$ signs by assessing pulmonary artery diameter (PAd) and RV enlargement in addition to PASP. ${ }^{10}$ Whether a novel comprehensive echocardiography scoring index (ESI) derived from additional $\mathrm{PH}$ signs and PASP could improve the value of echocardiography for predicting severe PH was unknown.

Since patients with CLD accompanied by severe $\mathrm{PH}$ have a much poorer prognosis, this population attracts clinicians' attention, particularly because early and adequate treatment is needed to improve patient prognosis. Furthermore, it remains undetermined whether the assessment of a comprehensive ESI is beneficial for predicting severe PH. In the current study, we aimed to analyze the value of a comprehensive ESI for predicting severe PH in patients with CLD.

\section{Materials and methods Ethics}

This study was conducted in accordance with the amended Declaration of Helsinki. The Local Institutional Ethics Committee of Shanghai Pulmonary Hospital approved the protocol (K08-015C), and written informed consent was obtained from all the patients in the validation cohort.

\section{Study design}

The retrospective derivation cohort and the prospective validation cohort were obtained from the Cardio-Pulmonary Circulation Center of Shanghai Pulmonary Hospital, which is the largest referral center for the diagnosis and treatment of $\mathrm{PH}$ in Shanghai, People's Republic of China. ${ }^{11}$ For the derivation cohort, all consecutive patients with CLD hospitalized between January 2012 and December 2014 who were suspected of $\mathrm{PH}$ were included for model derivation. The validation cohort included a similar population recruited between January 2015 and July 2015 for model verification.

\section{Inclusion and exclusion criteria}

The patient inclusion criteria were as follows: 1) suspected PH associated with CLD; ${ }^{12} 2$ ) diagnosis of CLD confirmed by experienced specialists according to the appropriate guidelines; ${ }^{13,14}$ and 3) performance of RHC and Doppler echocardiography at a clinically stable stage during optimal medical therapy.

Patients were excluded for the following reasons: 1) diagnosis of other types of $\mathrm{PH}$ as per the NICE criteria; ${ }^{12}$ 2) lack of RHC or echocardiography at a clinically stable stage; or 3) comorbidity of pulmonary embolism, severe left heart disease, and so on.

\section{Procedures}

A comprehensive set of quantitative echocardiography parameters was measured at rest (Vivid7 Dimension; GE Vingmed Ultrasound AS, Horten, Norway). The protocol and reference limits were in accordance with the current guidelines. ${ }^{15}$ Right ventricular end-diastolic transverse dimension (RVEDTD), right ventricular end-diastolic longitudinal dimension (RVEDLD), right atrial transverse dimension (RATD), right atrial longitudinal dimension (RALD), and end-systolic-stage eccentricity index (ENDSEI) were measured to indicate the presence or absence of right heart enlargement. ${ }^{15}$ PASP was measured by TRV with right atrium pressure (RAP) estimated by inferior cava diameter and inspiratory collapse. ${ }^{15}$ The PAd was also measured. ${ }^{15}$ RV function was assessed by measuring the tricuspid annular plane systolic excursion (TAPSE).${ }^{15}$ Left ventricular ejection fraction was measured using M-mode in the parasternal long-axis view.

RHC was performed as described previously. ${ }^{16}$ The baseline hemodynamic variables evaluated included mPAP, RAP, pulmonary artery wedge pressure (PAWP), cardiac output (CO), cardiac index, and PVR. 
All patients underwent RHC and echocardiography within 7 days at a clinically stable stage. Echocardiography was performed by two cardiologists (RJ and Q-HZ) who were blinded to all patients' medical history and RHC results. Similarly, the doctors who performed RHC were also blinded to the echocardiography results.

\section{Statistical analysis}

Continuous variables are described as the mean \pm SD and median (interquartile range) for normally distributed variables and skewed distributed variables, respectively. Categorical variables are expressed as percentages. Pearson correlation coefficients for PASP between RHC and echocardiography (abbreviated as $\mathrm{PASP}_{\mathrm{RHC}}$ and $\mathrm{PASP}_{\mathrm{ECHO}}$, respectively) were calculated.

All echocardiography parameters were used to model the probability of having severe $\mathrm{PH}$ by means of binary logistic regression. ${ }^{17}$ A stepwise selection procedure was used to find independent predictors of severe $\mathrm{PH}$ with p-to-enter of $\leq 0.10$ and p-to-remove of $\geq 0.15$. Variables assigned based on multiples of their rounded $\beta$-coefficients from the refitted model were used to define an ESI. All patients were classified into either the normal/PH group or the severe $\mathrm{PH}$ group. The receiver-operating characteristic (ROC) method was used to assess the ability of echocardiography variables and ESI to predict severe PH. The sensitivity, specificity, positive predictive value (PPV), and negative predictive value (NPV) were calculated.

To verify the ESI's diagnostic ability, we conducted an internal and prospective validation. Landis and $\mathrm{Koch}^{18}$ defined kappa values of $0.00-0.20$ as slight, $0.21-0.40$ as fair, $0.41-0.60$ as moderate, $0.61-0.80$ as substantial, and $0.81-1.00$ as almost perfect agreement. CIs were calculated with the adjusted percentile bootstrap method $(n=10,000$ replicates).

In all univariate analyses, $P \leq 0.05$ was considered statistically significant. All statistical methods were performed using SPSS 21.0 software (SPSS Inc., Chicago, IL, USA) and GraphPad Prism 5.04 software (GraphPad Software, Inc., San Diego, CA, USA).

\section{Results \\ Derivation cohort}

A total of 369 patients with CLD and suspected PH were admitted to our center between January 2012 and December 2014, of whom 107 underwent echocardiography $\leq 7$ days before RHC (mean 3.3 \pm 1.3 days before RHC; Figure 1).
369 patients with CLD with suspected

PH between 2012 and 2014

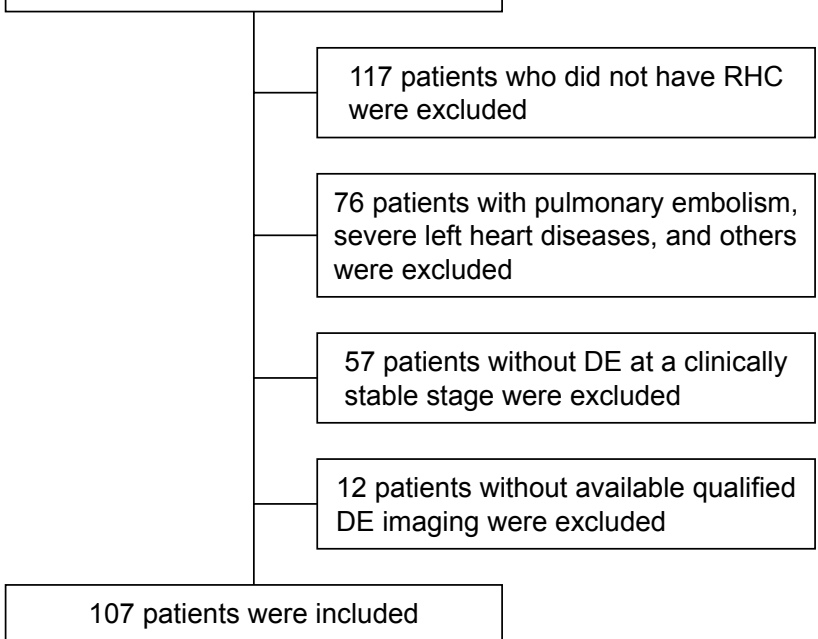

Figure I Flow diagram for the main derivation cohort. Of the 369 patients with CLD and suspected PH who were referred to the Cardio-Pulmonary Circulation Center of Shanghai Pulmonary Hospital within the study period, 107 met the inclusion criteria and were considered in the analysis.

Abbreviations: CLD, chronic lung disease; $\mathrm{PH}$, pulmonary hypertension; RHC right heart catheterization; DE, Doppler echocardiography.

Fifty-six patients with severe $\mathrm{PH}$ and 51 patients with normal/PH with a median age of $62.0(54.0,67.5)$ years and consisting of $63.8 \%$ men were included. A small proportion of patients had significant comorbidities, such as systemic hypertension (19.0\%), diabetes mellitus (3.9\%), coronary heart disease (4.8\%), arrhythmia (9.5\%), and hyperlipidemia $(2.9 \%)$ (Table 1). There were no significant differences in demographic characteristics, diagnostic classification, World Health Organization function class (WHO-FC), comorbidities, or pulmonary function test results between the groups (Table 1).

The PASP ${ }_{\mathrm{ECHO}}$ was measured at a clinically stable stage in $86.9 \%$ of all patients, which included $80.4 \%$ of the normal/ PH group and $92.8 \%$ of the severe PH group. There was a moderately strong correlation between $\mathrm{PASP}_{\mathrm{ECHO}}$ and both $\mathrm{PASP}_{\mathrm{RHC}}$ and $\mathrm{mPAP}_{\mathrm{RHC}}(r=0.665$ and $r=0.650$, both $P<0.001)$. Compared with the normal/PH group, the severe $\mathrm{PH}$ group showed significant abnormalities in the variables of echocardiography and RHC (all $P<0.001$ ) (Table 1).

Multivariate analyses were performed to construct the ESI. Age, RATD, RALD, RVEDLD, and ENDSEI were excluded due to nonsignificant results by multivariate analysis, despite achieving statistical significance by univariate analysis. Stepwise logistic regression analysis revealed four variables that were independently significant: RVEDTD, PASP, PAd, and TAPSE. The formula for ESI 
Table I Demographic characteristics, pulmonary function test results, hemodynamics, and echocardiography parameters of patients with normal/PH vs severe $\mathrm{PH}$

\begin{tabular}{|c|c|c|c|}
\hline Variable & $\begin{array}{l}\text { Normal/PH } \\
(n=5 I)\end{array}$ & $\begin{array}{l}\text { Severe PH } \\
(n=56)\end{array}$ & $P$-value \\
\hline Age (years) & $64.0(57.5,70.5)$ & $61.0(48.0,67.8)$ & 0.059 \\
\hline Men & $30(66.7 \%)$ & $37(61.7 \%)$ & 0.638 \\
\hline BSA $\left(m^{2}\right)$ & $1.6 \pm 0.2$ & $1.6 \pm 0.2$ & 0.543 \\
\hline \multicolumn{4}{|l|}{ Diagnosis } \\
\hline COPD & $35(68.6 \%)$ & $40(71.4 \%)$ & 0.753 \\
\hline Interstitial lung disease & $4(7.8 \%)$ & $6(10.7 \%)$ & 0.612 \\
\hline \multicolumn{4}{|c|}{ Other diseases with mixed restrictive and obstructive pattern } \\
\hline Combined pulmonary fibrosis and emphysema & I (2.0\%) & $\mathrm{I}(\mathrm{I} .8 \%)$ & 0.947 \\
\hline Lobectomia pulmonalis & $3(5.9 \%)$ & $\mathrm{I}(\mathrm{I} .8 \%)$ & 0.267 \\
\hline Chest deformity & I (2.0\%) & $\mathrm{I}(\mathrm{I} .8 \%)$ & 0.947 \\
\hline Lung destruction due to tuberculosis & $3(5.9 \%)$ & $2(3.6 \%)$ & 0.573 \\
\hline Bronchiectasis & I (2.0\%) & $3(5.4 \%)$ & 0.357 \\
\hline Pneumoconiosis & I (2.0\%) & $0(1.7 \%)$ & 0.295 \\
\hline Sleep-disordered breathing & I (2.0\%) & $2(3.6 \%)$ & 0.616 \\
\hline Alveolar hypoventilation disorders & I (2.0\%) & 0 & 0.295 \\
\hline \multicolumn{4}{|l|}{ Comorbidities } \\
\hline Systemic hypertension & $10(22.2 \%)$ & $10(16.7 \%)$ & 0.616 \\
\hline Diabetes mellitus & $3(6.7 \%)$ & I (I.7\%) & 0.311 \\
\hline Coronary heart disease & $4(8.9 \%)$ & I (I.7\%) & 0.162 \\
\hline Malignant tumor & 0 & $\mathrm{I}(\mathrm{I} .7 \%)$ & 0.386 \\
\hline Arrhythmia & $6(13.3 \%)$ & $4(6.7 \%)$ & 0.320 \\
\hline Hyperlipidemia & $3(6.7 \%)$ & 0 & 0.076 \\
\hline Previous cerebral infarction & 0 & I (I.7\%) & 0.386 \\
\hline \multicolumn{4}{|l|}{ Pulmonary function test } \\
\hline $\mathrm{FEV}_{1} \%$ predicted & $48.8 \pm 23.3$ & $48.5 \pm 21.0$ & 0.309 \\
\hline FVC \% predicted & $67.5 \pm 25.4$ & $62.0 \pm 20.7$ & 0.664 \\
\hline $\mathrm{FEV}_{1} / \mathrm{FVC} \%$ predicted & $57.7 \pm 18.2$ & $61.9 \pm 16.1$ & 0.409 \\
\hline RV \% predicted & $178.9 \pm 62.9$ & $156.3 \pm 55.3$ & 0.178 \\
\hline TLC \% predicted & $109.5 \pm 27.4$ & $101.2 \pm 19.6$ & 0.197 \\
\hline DLco \% predicted & $51.4 \pm 27.4$ & $57.6 \pm 33.9$ & 0.471 \\
\hline \multicolumn{4}{|l|}{ Hemodynamics } \\
\hline $\mathrm{mRAP}(\mathrm{mmHg})$ & $4.0(2.0,5.0)$ & $7.0(4.0,9.0)$ & $<0.001$ \\
\hline mPAP $(\mathrm{mmHg})$ & $29.0(24.5,32.0)$ & $47.0(41.0,57.5)$ & $<0.001$ \\
\hline PAWP (mmHg) & $8.1 \pm 3.4$ & $9.9 \pm 4.3$ & 0.022 \\
\hline $\mathrm{CO}(\mathrm{L} / \mathrm{min})$ & $5.7(4.3,6.6)$ & $4.7(4.0,5.7)$ & 0.034 \\
\hline Cardiac index $\left(\mathrm{L} / \mathrm{min} / \mathrm{m}^{2}\right)$ & $3.5 \pm 0.8$ & $3.2 \pm 1.0$ & 0.192 \\
\hline PVR (Wood units) & $3.6(2.4,4.8)$ & $7.9(6.2,10.2)$ & $<0.001$ \\
\hline \multicolumn{4}{|l|}{ Echocardiography } \\
\hline LVEF (\%) & $69.1 \pm 7.6$ & $71.3 \pm 9.3$ & 0.186 \\
\hline $\operatorname{RATD}(\mathrm{cm})$ & $4.0(3.5,4.7)$ & $4.8(3.2,5.5)$ & $<0.001$ \\
\hline RALD $(\mathrm{cm})$ & $4.5(3.9,5.4)$ & $5.2(4.5,6.0)$ & 0.005 \\
\hline RVEDTD $(\mathrm{cm})$ & $3.5(3.1,3.9)$ & $4.3(3.8,5.0)$ & $<0.001$ \\
\hline RVEDLD $(\mathrm{cm})$ & $5.8(5.5,6.7)$ & $6.5(5.8,7.1)$ & 0.011 \\
\hline PASP $(\mathrm{mmHg})$ & $47.4 \pm 11.6$ & $76.0 \pm 21.9$ & $<0.001$ \\
\hline TAPSE $(\mathrm{cm})$ & $2.0 \pm 0.3$ & $1.7 \pm 0.3$ & $<0.001$ \\
\hline PAd $(\mathrm{cm})$ & $2.4(2.2,2.7)$ & $2.8(2.6,3.2)$ & $<0.001$ \\
\hline ENDSEI & $1.0(1.0,1.1)$ & $1.3(1.1,1.5)$ & $<0.001$ \\
\hline PASP - yes & $4 \mathrm{I}(80.4 \%)$ & 52 (92.9\%) & 0.057 \\
\hline
\end{tabular}

Note: Data shown as mean $\pm \mathrm{SD}, \mathrm{n}(\%)$ or median (quartile range).

Abbreviations: PH, pulmonary hypertension; BSA, body surface area; FEV , forced expiratory volume in I s; FVC, forced vital capacity; RV, residual volume; TLC, total lung capacity; DLco, diffusing capacity for carbon monoxide; mRAP, mean right atrium pressure; mPAP, mean pulmonary artery pressure; PAWP, pulmonary artery wedge pressure; CO, cardiac output; PVR, pulmonary vascular resistance; LVEF, left ventricular ejection fraction; RATD, right atrial transverse dimension; RALD, right atrial longitudinal dimension; RVEDTD, right ventricular end-diastolic transverse dimension; RVEDLD, right ventricular end-diastolic longitudinal dimension; PASP, pulmonary arterial systolic pressure; TAPSE, tricuspid annular plane systolic excursion; PAd, pulmonary artery diameter; ENDSEI, end-systolic-stage eccentricity index. 
Table 2 Logistic regression analysis of echocardiography parameters associated with severe $\mathrm{PH}$

\begin{tabular}{|c|c|c|c|c|c|c|}
\hline \multirow[t]{2}{*}{ Variable* } & \multicolumn{2}{|l|}{ Univariate analysis } & \multirow[t]{2}{*}{$\beta$-coefficient } & \multirow{2}{*}{$\begin{array}{l}\text { Weighted } \\
\text { scores }\end{array}$} & \multicolumn{2}{|l|}{ Multivariate analysis } \\
\hline & OR $(95 \% \mathrm{CI})$ & $P$-value & & & OR (95\% CI) & $P$-value \\
\hline RATD $(\mathrm{cm})$ & $5.249(2.262,12.389)$ & $<0.001$ & - & - & - & - \\
\hline RALD (cm) & $4.491(2.138,11.418)$ & $<0.001$ & - & - & - & - \\
\hline RVEDTD $(\mathrm{cm})$ & I0.77| (4.3|I, 26.909) & $<0.001$ & 1.665 & $2^{\dagger}$ & $5.283(1.368,20.403)$ & 0.016 \\
\hline RVEDLD (cm) & $3.229(1.426,7.313)$ & 0.005 & - & - & - & - \\
\hline PASP $(\mathrm{mmHg})$ & $23.688(8.383,66.940)$ & $<0.001$ & 2.981 & $3^{\dagger}$ & $19.710(5.032,77.206)$ & $<0.001$ \\
\hline PAd $(\mathrm{cm})$ & $6.889(2.789,17.015)$ & $<0.001$ & 1.941 & $2^{\dagger}$ & $6.963(1.803,26.893)$ & 0.005 \\
\hline ENDSEI & I6.593 (4.62I, 59.58I) & $<0.001$ & - & - & - & - \\
\hline TAPSE $(\mathrm{cm})$ & $0.168(0.058,0.488)$ & 0.001 & -2.864 & $-3^{\dagger}$ & $0.057(0.010,0.320)$ & 0.001 \\
\hline
\end{tabular}

Notes: *Variables were transformed into binary variables according to optimum cutoff values. ${ }^{\dagger} \mid \mathrm{f} R$ VEDTD $\geq 3.8 \mathrm{~cm}$ or $\mathrm{PAd} \geq 2.7 \mathrm{~cm}$, weighted score $=+2$; if $\mathrm{PASP} \geq 6 \mathrm{I} \mathrm{mmHg}$, weighted score $=+3$; and if TAPSE $\geq 1.65 \mathrm{~cm}$, weighted score $=-3$.

Abbreviations: PH, pulmonary hypertension; RATD, right atrial transverse dimension; RALD, right atrial longitudinal dimension; RVEDTD, right ventricular end-diastolic transverse dimension; RVEDLD, right ventricular end-diastolic longitudinal dimension; PASP, pulmonary arterial systolic pressure; PAd, pulmonary artery diameter; ENDSEI, end-systolic-stage eccentricity index; TAPSE, tricuspid annular plane systolic excursion.

was derived from the $\beta$-coefficients in the final model (Table 2): $\mathrm{ESI}=\mathrm{ESI}_{\mathrm{RVEDTD}}+\mathrm{ESI}_{\mathrm{PASP}}+\mathrm{ESI}_{\mathrm{PAd}}-\mathrm{ESI}_{\mathrm{TAPSE}}$.

Based on ROC analysis, PASP $\geq 61 \mathrm{mmHg}$ displayed $80.4 \%$ sensitivity and $84.3 \%$ specificity with an area under ROC curve (AUC) of 0.823 (95\% CI: $0.797-0.942, P<0.0001$ ).

The other parameters, except for RVEDTD, did not seem to have good sensitivity and specificity for predicting severe PH (Table 3). Compared with PASP ${ }_{\mathrm{ECHO}}$, the ESI resulted in a net improvement in model performance, with a change in the $c$-statistic from 0.823 to 0.937 (95\% CI: $0.890-0.984$, $P<0.001)$ and an integrated discrimination improvement of $11.3 \%$ (95\% CI: $4.5 \%-18.2 \%, P=0.001$ ) (Figure 2).

Table 3 The distribution of echocardiography parameters and accuracy for discrimination

\begin{tabular}{|c|c|c|c|c|c|c|c|}
\hline Variable & $\begin{array}{l}\text { All subjects } \\
(n=107)\end{array}$ & $\begin{array}{l}\text { Normal/PH } \\
(n=51)\end{array}$ & $\begin{array}{l}\text { Severe PH } \\
(n=56)\end{array}$ & $P$-value & $\begin{array}{l}\text { Sensitivity } \\
\text { (\%) }\end{array}$ & $\begin{array}{l}\text { Specificity } \\
\text { (\%) }\end{array}$ & $\begin{array}{l}\text { Area under the } \\
\text { curve }(95 \% \mathrm{Cl})\end{array}$ \\
\hline \multicolumn{8}{|c|}{$\operatorname{RATD}(\mathrm{cm})$} \\
\hline$<4.2$ & $46(43.0)$ & $33(64.7)$ & $13(23.2)$ & $<0.001$ & 0.768 & 0.647 & $0.707(0.607,0.807)$ \\
\hline$\geq 4.2$ & $61(57.0)$ & $18(35.3)$ & $43(76.8)$ & & & & \\
\hline \multicolumn{8}{|c|}{ RALD $(\mathrm{cm})$} \\
\hline$<4.8$ & $52(48.6)$ & $35(68.6)$ & $17(30.4)$ & 0.008 & 0.696 & 0.686 & $0.650(0.543,0.756)$ \\
\hline$\geq 4.8$ & $55(51.4)$ & $16(31.4)$ & $39(69.6)$ & & & & \\
\hline \multicolumn{8}{|c|}{ RVEDTD $(\mathrm{cm})$} \\
\hline$<3.8$ & $47(43.9)$ & $14(27.5)$ & $10(17.9)$ & $<0.001$ & 0.821 & 0.725 & $0.80 \mathrm{I}(0.7 \mathrm{I} 6,0.886)$ \\
\hline$\geq 3.8$ & $60(56.1)$ & $37(72.5)$ & $46(82.1)$ & & & & \\
\hline \multicolumn{8}{|c|}{ RVEDLD $(\mathrm{cm})$} \\
\hline$<6.4$ & $61(57.0)$ & $14(27.5)$ & II (19.6) & 0.002 & 0.571 & 0.725 & $0.672(0.569,0.774)$ \\
\hline$\geq 6.4$ & $46(43.0)$ & $37(72.5)$ & $45(80.4)$ & & & & \\
\hline \multicolumn{8}{|c|}{ PASP (mmHg) } \\
\hline$<61$ & $54(50.5)$ & $43(84.3)$ & II (19.6) & $<0.001$ & 0.804 & 0.843 & $0.869(0.797,0.942)$ \\
\hline$\geq 6 \mathrm{I}$ & $53(49.5)$ & $8(15.7)$ & $45(80.4)$ & & & & \\
\hline \multicolumn{8}{|l|}{ PAd $(\mathrm{cm})$} \\
\hline$<2.7$ & $57(53.3)$ & $39(76.5)$ & $18(32.1)$ & $<0.00$ I & 0.679 & 0.765 & $0.745(0.675,0.855)$ \\
\hline$\geq 2.7$ & $50(46.7)$ & $12(23.5)$ & $38(67.9)$ & & & & \\
\hline \multicolumn{8}{|l|}{ ENDSEI } \\
\hline$<1.05$ & $48(46.9)$ & $35(68.6)$ & $13(23.3)$ & $<0.001$ & 0.768 & 0.683 & $0.792(0.706,0.878)$ \\
\hline$\geq 1.05$ & $59(55.1)$ & $16(31.4)$ & $43(76.8)$ & & & & \\
\hline \multicolumn{8}{|c|}{ TAPSE $(\mathrm{cm})$} \\
\hline$<1.65$ & $27(25.2)$ & $5(9.8)$ & $22(39.3)$ & 0.001 & 0.902 & 0.607 & $0.684(0.584,0.784)$ \\
\hline$\geq 1.65$ & $80(74.8)$ & $46(90.2)$ & $34(60.7)$ & & & & \\
\hline
\end{tabular}

Note: Data shown as $\mathrm{n}(\%)$.

Abbreviations: PH, pulmonary hypertension; RATD, right atrial transverse dimension; RALD, right atrial longitudinal dimension; RVEDTD, right ventricular end-diastolic transverse dimension; RVEDLD, right ventricular end-diastolic longitudinal dimension; PASP, pulmonary arterial systolic pressure; PAd, pulmonary artery diameter; ENDSEl, end-systolic-stage eccentricity index; TAPSE, tricuspid annular plane systolic excursion. 


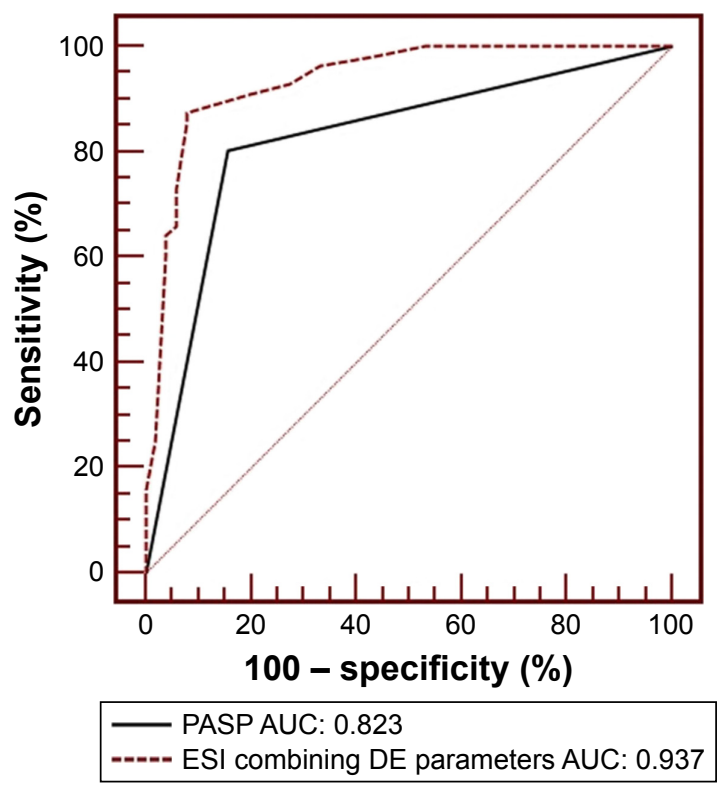

Figure 2 The receiver-operator characteristic curve is shown for PASP alone as determined by echocardiography variables and for ESI in predicting severe $\mathrm{PH}$. Abbreviations: PASP, pulmonary arterial systolic pressure; ESI, echocardiography scoring index; $\mathrm{PH}$, pulmonary hypertension; AUC, area under the curve; DE, Doppler echocardiography.

Since severe PH should capture clinicians' attention due to its poor prognosis, to minimize the chance of overlooking a case of severe $\mathrm{PH}$, we examined several alternate cutoff values of the ESI and determined the cutoff value that maximized sensitivity with the least compromise in specificity (Table S1). Therefore, we chose 1.0 as the optimal cutoff value for the ESI. With ESI $\geq 1.0$ as the definition of a model-predicted case of severe $\mathrm{PH}$, the sensitivity, specificity, PPV, and NPV were $91.1 \%, 80.4 \%, 83.6 \%$, and $89.1 \%$, respectively.

Figure 3 shows representative echocardiography traces from two patients with CLD who were verified as having mild or severe PH on RHC.

\section{Validation cohort}

A total of 127 patients with CLD and suspected PH between Jan 2015 and Jul 2015 were admitted to our center, of whom 16 adult patients had normal/mild PH and 19 had severe PH. Clinical data are presented in Tables S2 and S3. A trend towards lower PASP ${ }_{\mathrm{ECHO}}$ or PASP ${ }_{\mathrm{RHC}}$ and mean RAP was seen in the validation cohort. The ESI was validated in the cohort with $84.2 \%$ sensitivity, $81.3 \%$ specificity, $84.2 \%$ PPV, $81.3 \%$ NVP, and $82.9 \%$ accuracy. The ESI showed precise and substantial kappa agreement (0.655, 95\% CI: 0.370-0.884).

\section{Discussion}

We derived and validated a comprehensive ESI by combining additional $\mathrm{PH}$ signs and $\mathrm{PASP}_{\mathrm{ECHO}}$ for predicting severe
PH in patients with CLD. ESI $\geq 1.0$ displayed satisfactory sensitivity, specificity, PPV, NPV, and accuracy in predicting severe $\mathrm{PH}$ and is recommended to be applied in clinical practice due to its noninvasive nature and cost effectiveness.

Despite availability of targeted PH medication for PAH, no targeted medication is approved at the moment for PH in CLD and use of targeted drugs would be off-label. Compared with patients with CLD in the normal/PH group, patients in the severe $\mathrm{PH}$ group exhibited poorer prognosis and higher mortality. ${ }^{10,19}$ Therefore, it is important for clinicians to detect severe $\mathrm{PH}$ in patients earlier and to initiate adequate treatment in order to improve patient prognosis. RHC is the gold standard for measuring not only mPAP but also PAWP, cardiac index, CO, and PVR. RHC cannot be replaced by echocardiography. Nevertheless, RHC cannot be performed in every hospital, especially in the People's Republic of China. Sometimes, patients are not willing to undergo RHC during follow-up because of its invasiveness and cost. However, as a PH-screening tool, PASP can be estimated by measuring the peak TRV on echocardiography, which continues to be recommended for early screening and assessment in patients with idiopathic $\mathrm{PAH}$, chronic thromboembolism-associated $\mathrm{PH}$, or connective tissue disease-associated PAH. ${ }^{20}$ However, PASP estimation is often inaccurate, especially in patients with CLD, and requires the presence of sufficient tricuspid regurgitation (TR), proper Doppler alignment, and optimal visualization of the regurgitant jet. Moreover, the absence of TR is not sufficient to exclude PH, and the TRV might be underestimated in patients with CLD who have hyperinflation of the lungs and marked respiratory variations in intrathoracic pressure. ${ }^{9}$ Even if a TR is observed, $\mathrm{PAP}_{\mathrm{ECHO}}$ is often inaccurate and leads to both false-positive and false-negative diagnoses of $\mathrm{PH},{ }^{19}$ not to mention an inability to determine severe $\mathrm{PH}$. Compared with PASP $_{\mathrm{RHC}}$, PASP $_{\mathrm{ECHO}}$ was found to be inaccurate in $52 \%$ of COPD cases, with a tendency to overestimate PAP. ${ }^{9}$ Indeed, $48 \%$ of patients were misclassified as having PH by echocardiography alone. ${ }^{9,21}$ In addition, some studies have identified a strong relationship between $\mathrm{MPAP}_{\mathrm{ECHO}}$ and $\mathrm{mPAP}_{\mathrm{RHC} \cdot{ }^{22} \text { However, the diagnostic utility of } \mathrm{mPAP}}$ for specific underlying etiologies, such as emphysema, has been questioned. ${ }^{21}$ In other studies, ${ }^{9,23} \mathrm{PASP}_{\mathrm{ECHO}}$ predicted PH in patients with CLD with 76\%-85\% sensitivity, 17\%-38\% specificity, 56\%-60\% PPV, and 44\%-60\% NPV. Consequently, $\mathrm{PASP}_{\mathrm{ECHO}}$ and $\mathrm{mPAP}_{\mathrm{ECHO}}$ have not yet been adopted as stand-alone tools capable of accurately measuring pulmonary hemodynamics.

At present, this ESC guideline suggests grading the probability of PH based on TRV and additional prespecified 
A

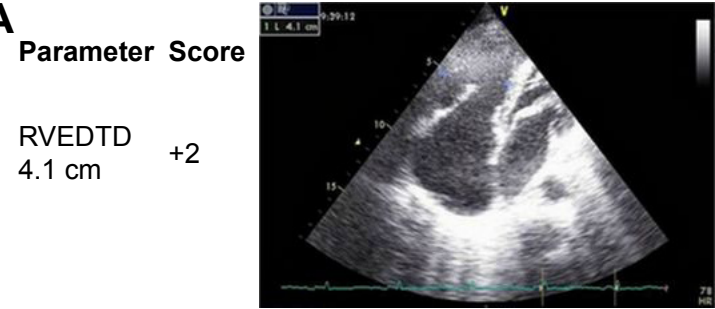

PAd

$2.5 \mathrm{~cm}$

0

PASP

$49 \mathrm{mmHg} O$

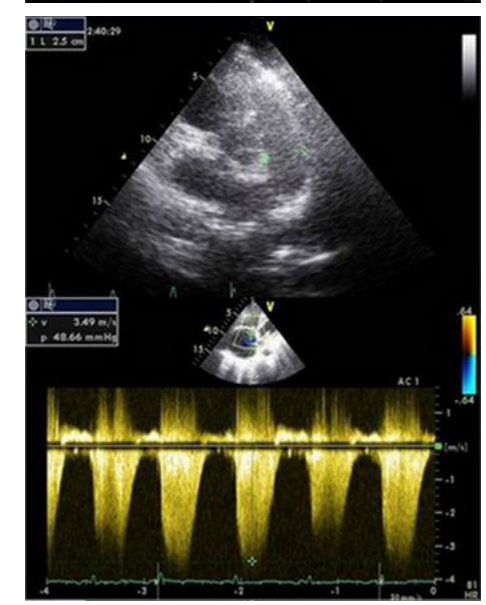

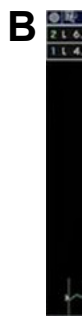

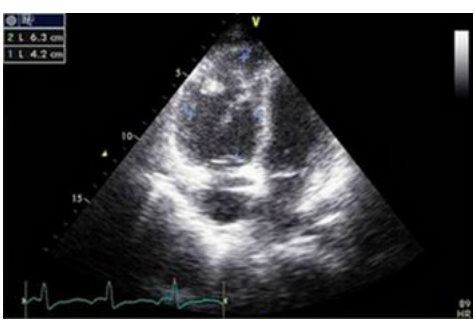

Parameter Score

RVEDTD

$4.2 \mathrm{~cm}$

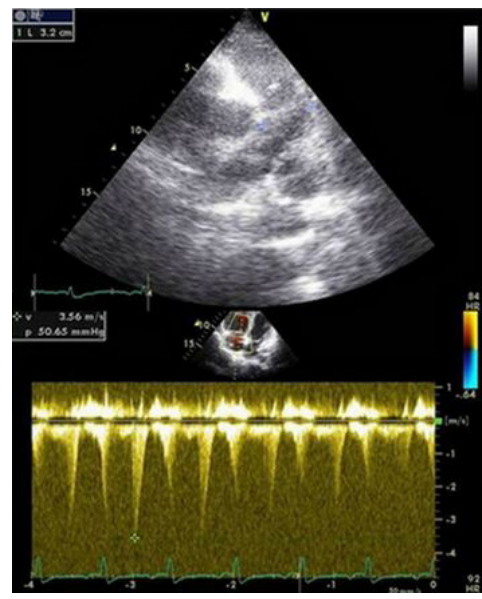

PAd

$3.2 \mathrm{~cm}$

$+2$

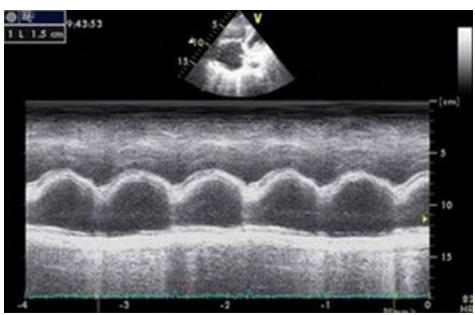

PASP

$51 \mathrm{mmHg}$

TAPSE

$1.5 \mathrm{~cm}$

$\mathrm{ESI}=+4$

Figure 3 Representative echocardiographic images of RVEDTD, PASP, PAd, and tricuspid annular plane systolic excursion as well as the score calculation for two patients. Column A (top to bottom) shows $\uparrow$ RVEDTD and $\uparrow$ PASP (score $=-1$ ). Invasive hemodynamics: $\mathrm{mPAP}=30 \mathrm{mmHg}, \mathrm{PAWP}=\mathrm{II} \mathrm{mmHg}, \mathrm{PVR}=6.0 \mathrm{Wood}$ units, and cardiac index $=3.1 \mathrm{~L} / \mathrm{min} / \mathrm{m}^{2}$. Column B shows $\uparrow$ RVEDTD, $\uparrow P A S P$, $\uparrow P A d$, and $\downarrow$ TAPSE (score $=4$ ). Invasive hemodynamics: $\mathrm{mPAP}=39 \mathrm{mmHg}, \mathrm{PAWP}=\mathrm{II} \mathrm{mmHg}, \mathrm{PVR}=6.0 \mathrm{Wood}$ units, and cardiac index $=3.35 \mathrm{~L} / \mathrm{min} / \mathrm{m}^{2}$.

Abbreviations: RVEDTD, right ventricular end-diastolic transverse dimension; PASP, pulmonary arterial systolic pressure; PAd, pulmonary artery diameter; mPAP, mean pulmonary artery pressure; PAWP, pulmonary artery wedge pressure; PVR, pulmonary vascular resistance; TAPSE, tricuspid annular plane systolic excursion; ESI, echocardiography scoring index.

echocardiographic variables that are suggestive of $\mathrm{PH} .{ }^{10}$ Additional signs of $\mathrm{PH}$ such as RV dilation, eccentricity index, and $\mathrm{PAd}^{24}$ have been reported to discern PAH with high sensitivity. Many years ago, several studies derived and validated equations using additional $\mathrm{PH}$ signs to estimate $\mathrm{PVR}$ or mPAP as confirmed by RHC in patients with $\mathrm{PH} .{ }^{4,5,23}$ Prior studies have tried but failed to utilize acceleration time in the right ventricular outflow tract (RVOT) to measure PAP or predict $\mathrm{PH}$ in patients with CLD. ${ }^{25,26}$ Opotowsky et al reported that the RVOT velocity or RVOT velocity time integral has been proposed as a PVR prediction model ${ }^{5,8}$ for determining the severity of $\mathrm{PH}$ with the exception of $\mathrm{PH}$ due to $\mathrm{CLD}^{24}$ or for estimating PAP in children with CLD. ${ }^{27}$ However, the abovestated methods were slightly more cumbersome, and we favor simply measured variables to increase clinical utility.

In our research, we derived a novel comprehensive index by combining RVEDTD, PAd, and TAPSE in addition to
$\mathrm{PASP}_{\mathrm{ECHO}}$. This index has several advantages. First, the ESI's sensitivity and specificity are substantially higher than PASP $_{\text {ECHO }}$, with an increase in the $c$-statistic from 0.823 to 0.937. Second, the four variables are not cumbersome to measure and are easy to obtain. Third, the ESI is noninvasive, reliable, and easy to integrate into clinical practice, especially during follow-up.

D'Alto et $\mathrm{al}^{6}$ reported that echocardiography allows for accurate measurements of pulmonary circulation but with moderate precision by Bland-Altman analysis, which explains why the procedure is valid for population studies but cannot be used for the diagnosis of $\mathrm{PH}$ in individual patients. Because our research objective is to make a cutoff value to differentiate "severe $\mathrm{PH}$ " from "normal/PH" rather than replace gold criterion by new parameter, Bland-Altman analysis might not be suitable for our research. We calculated accuracy and precision in accordance with categorical 
variable and kappa, respectively. In our study, there were no significant biases, and the ESI showed $82.9 \%$ accuracy in the validation cohort. However, the ESI had a kappa statistic of 0.655 , indicating substantial but not high agreement. Our results are consistent with earlier reports and could help clinicians perform preliminary screening of patients with suspected severe PH.

Although the parameter for the discrimination of severe $\mathrm{PH}$ is an mPAP of $35 \mathrm{mmHg}$ by RHC, the corresponding PASP $_{\text {ECHO }}$ of $61 \mathrm{mmHg}$ derived from the sample seems very high. This is far greater than the calculated PASP of $53 \mathrm{mmHg}^{7}$ or $54 \mathrm{mmHg}^{28}$ for an mPAP of $35 \mathrm{mmHg}$. This indicates that $\mathrm{PASP}_{\mathrm{ECHO}}$ was not sufficient for predicting $\mathrm{PH}$ in patients with CLD.

As we know, the severity of $\mathrm{PH}$ should not be judged by PAP but rather by clinical outcomes such as WHO-FC, hospitalization, RHF, up-titration of medications, transplantation, or mortality. However, our research was a diagnostic study that validated the capacity of a comprehensive echocardiography index for predicting severe $\mathrm{PH}$ in patients with CLD. In the future, our research would be strengthened by determining the predictive nature of the formula in clinical outcomes from the validation cohort. A formula that could predict clinical outcomes in this population would be more useful. We will further consider this problem when we have a large patient cohort that can be followed over time and will develop a formula based on those data.

\section{Study limitations}

This study has several limitations that need to be considered when interpreting the results. First, this was a single-center study, which may have patient selection bias because not all the patients with CLD had undergone RHC. However, patients admitted into our center came from all over People's Republic of China, which may reduce bias. Second, echocardiography and RHC were not conducted simultaneously; therefore, the delay between procedures could be considered a limitation of this study. However, the included patients received similar levels of support and treatment at the times of echocardiography and RHC, and there were no detectable differences in medications or fluid status between the two groups. All patients underwent RHC at a clinically stable stage, manifesting relief of respiratory failure and RHF. The number of days between echocardiography and RHC was also validated as insignificant by logistical regression. Importantly, the strength of the present study is the evaluation of these tests through actual application in clinical practice.

\section{Conclusion}

We present a simple clinical tool that helps to predict severe $\mathrm{PH}$ in patients with CLD. The integrated ESI combining additional $\mathrm{PH}$ signs and $\mathrm{PASP}_{\mathrm{ECHO}}$ improved the accuracy of predicting severe $\mathrm{PH}$ based on echocardiography. If patients with CLD have an ESI $>1.0$, they should receive clinicians' attention and should undergo RHC because they may have a high risk of severe $\mathrm{PH}$ and pulmonary vascular remodeling. Early diagnosis and treatment are crucial in this patient population.

\section{Acknowledgment}

This study was supported by the National Natural Science Foundation of China (81600032) and the YangFan Program of Shanghai Science and Technology Committee (15YF1409700).

\section{Author contributions}

Drs RJ, RZ, and J-ML contributed to the experimental design, study conduct, data analysis, and drafting and revising the manuscript. LW, Q-HZ, and PY contributed to the data collection and revising manuscript. BP, CW, W-HW, and $\mathrm{Z}-\mathrm{CJ}$ contributed to the experimental design, interpretation of data, and revising the manuscript. All authors had full access to all study data and had final responsibility for the decision to submit for publication. All have reviewed the manuscript and approved the final version for submission. All the authors ensured that questions related to the accuracy or integrity of any part of the work were appropriately investigated and resolved.

\section{Disclosure}

Prof Z-CJ serves as a consultant and scientific advisor to Actelion, Bayer Schering, AstraZeneca, Pfizer, and United Therapeutics, in addition to being an investigator in trials sponsored by these companies. The other authors report no conflicts of interest in this work.

\section{References}

1. Mourani PM, Sontag MK, Younoszai A, Ivy DD, Abman SH. Clinical utility of echocardiography for the diagnosis and management of pulmonary vascular disease in young children with chronic lung disease. Pediatrics. 2008;121(2):317-325.

2. Seeger W, Adir Y, Barberà JA, et al. Pulmonary hypertension in chronic lung diseases. J Am Coll Cardiol. 2013;62(25 Suppl):D109-D116.

3. Hoeper MM, Andreas S, Bastian A, et al. Pulmonary hypertension due to chronic lung disease: updated Recommendations of the Cologne Consensus Conference 2011. Int J Cardiol. 2011;154 Suppl 1:S45-S53.

4. Robinson B, Ebeid M. A simple echocardiographic method to estimate pulmonary vascular resistance. Am J Cardiol. 2014;113(2):412. 
5. Opotowsky AR, Clair M, Afilalo J, et al. A simple echocardiographic method to estimate pulmonary vascular resistance. Am J Cardiol. 2013; 112(6):873-882.

6. D'Alto M, Romeo E, Argiento P, et al. Accuracy and precision of echocardiography versus right heart catheterization for the assessment of pulmonary hypertension. Int J Cardiol. 2013;168(4):4058-4062.

7. Aduen JF, Castello R, Daniels JT, et al. Accuracy and precision of three echocardiographic methods for estimating mean pulmonary artery pressure. Chest. 2011;139(2):347-352.

8. Roule V, Labombarda F, Pellissier A, et al. Echocardiographic assessment of pulmonary vascular resistance in pulmonary arterial hypertension. Cardiovasc Ultrasound. 2010;8:21.

9. Arcasoy SM, Christie JD, Ferrari VA, et al. Echocardiographic assessment of pulmonary hypertension in patients with advanced lung disease. Am J Respir Crit Care Med. 2003;167(5):735-740.

10. Galiè N, Humbert M, Vachiery JL, et al. 2015 ESC/ERS Guidelines for the diagnosis and treatment of pulmonary hypertension: the Joint Task Force for the Diagnosis and Treatment of Pulmonary Hypertension of the European Society of Cardiology (ESC) and the European Respiratory Society (ERS): Endorsed by: Association for European Paediatric and Congenital Cardiology (AEPC), International Society for Heart and Lung Transplantation (ISHLT). Eur Heart J. 2016;37(1):67-119.

11. Zhang R, Dai LZ, Xie WP, et al. Survival of Chinese patients with pulmonary arterial hypertension in the modern treatment era. Chest. 2011;140(2):301-309.

12. Simonneau G, Gatzoulis MA, Adatia I, et al. Updated clinical classification of pulmonary hypertension. J Am Coll Cardiol. 2013;62(25 Suppl): D34-D41.

13. Vestbo J, Hurd SS, Agusti AG, et al. Global strategy for the diagnosis, management, and prevention of chronic obstructive pulmonary disease: GOLD executive summary. Am J Respir Crit Care Med. 2013;187(4): 347-365.

14. Meyer KC, Raghu G, Baughman RP, et al; American Thoracic Society Committee on BAL in Interstitial Lung Disease. An official American Thoracic Society clinical practice guideline: the clinical utility of bronchoalveolar lavage cellular analysis in interstitial lung disease. Am J Respir Crit Care Med. 2012;185(9):1004-1014.

15. Rudski LG, Lai WW, Afilalo J, et al. Guidelines for the echocardiographic assessment of the right heart in adults: a report from the American Society of Echocardiography endorsed by the European Association of Echocardiography, a registered branch of the European Society of Cardiology, and the Canadian Society of Echocardiography. J Am Soc Echocardiogr. 2010;23(7):685-713; quiz 786-788.
16. Jiang R, Ai ZS, Jiang X, et al. Intravenous fasudil improves in-hospital mortality of patients with right heart failure in severe pulmonary hypertension. Hypertens Res. 2015;38(8):539-544.

17. Thwaites GE, Chau TT, Stepniewska K, et al. Diagnosis of adult tuberculous meningitis by use of clinical and laboratory features. Lancet. 2002;360(9342):1287-1292.

18. Landis JR, Koch GG. The measurement of observer agreement for categorical data. Biometrics. 1977;33(1):159-174.

19. Barberà JA, Blanco I. Management of pulmonary hypertension in patients with chronic lung disease. Curr Hypertens Rep. 2015;17(8):62.

20. Pristera N, Musarra R, Schilz R, Hoit BD. The role of echocardiography in the evaluation of pulmonary arterial hypertension. Echocardiography. 2016;33(1):105-116.

21. Fisher MR, Criner GJ, Fishman AP, et al. Estimating pulmonary artery pressures by echocardiography in patients with emphysema. Eur Respir J. 2007;30(5):914-921.

22. Berger M, Haimowitz A, Van Tosh A, Berdoff RL, Goldberg E. Quantitative assessment of pulmonary hypertension in patients with tricuspid regurgitation using continuous wave Doppler ultrasound. J Am Coll Cardiol. 1985;6(2):359-365.

23. Zisman DA, Ross DJ, Belperio JA, et al. Prediction of pulmonary hypertension in idiopathic pulmonary fibrosis. Respir Med. 2007;101(10) 2153-2159.

24. López-Candales A, Edelman K. Shape of the right ventricular outflow Doppler envelope and severity of pulmonary hypertension. Eur Heart J Cardiovasc Imaging. 2012;13(4):309-316.

25. Marchandise B, De Bruyne B, Delaunois L, Kremer R. Noninvasive prediction of pulmonary hypertension in chronic obstructive pulmonary disease by Doppler echocardiography. Chest. 1987;91(3):361-365.

26. Torbicki A, Skwarski K, Hawrylkiewicz I, Pasierski T, Miskiewicz Z, Zielinski J. Attempts at measuring pulmonary arterial pressure by means of Doppler echocardiography in patients with chronic lung disease. Eur Respir J. 1989;2(9):856-860.

27. Newth CJ, Gow RM, Rowe RD. The assessment of pulmonary arterial pressures in bronchopulmonary dysplasia by cardiac catheterization and M-mode echocardiography. Pediatr Pulmonol. 1985;1(1):58-62.

28. Chemla D, Castelain V, Provencher S, Humbert M, Simonneau G, Hervé P. Evaluation of various empirical formulas for estimating mean pulmonary artery pressure by using systolic pulmonary artery pressure in adults. Chest. 2009;135(3):760-768. 


\section{Supplementary materials}

Table SI Sensitivity, specificity, positive predictive values, and negative predictive values of the diagnostic index

\begin{tabular}{lllll}
\hline Cutoff values & Sensitivity (\%) & Specificity (\%) & PPV (\%) & NPV (\%) \\
\hline Derivation cohort & & & & 92.5 \\
$\quad$ Cutoff $=1.5$ & 87.5 & 92.2 & 83.6 & 87.0 \\
$\quad$ Cutoff $=1.0$ & 91.1 & 80.4 & & 89.1 \\
Validation cohort & & & 78.6 & 62.5 \\
$\quad$ Cutoff $=1.5$ & 64.7 & 76.9 & 84.2 & 81.3 \\
Cutoff $=1.0$ & 81.3 & 84.2 & & \\
\hline
\end{tabular}

Abbreviations: PPV, positive predictive value; NPV, negative predictive value.

Table S2 Comparison of characteristics of patients of derivation cohort vs validation cohort

\begin{tabular}{|c|c|c|c|}
\hline Variable & $\begin{array}{l}\text { Derivation cohort } \\
(n=107)\end{array}$ & $\begin{array}{l}\text { Validation cohort } \\
(n=35)\end{array}$ & $P$-value \\
\hline Age (years) & $63.0(54.0,70.0)$ & $63.0(56.5,68.0)$ & 0.998 \\
\hline Men (\%) & 67 & 21 & 0.458 \\
\hline $\operatorname{BSA}\left(m^{2}\right)$ & $1.6(0.2)$ & $1.6(0.2)$ & 0.204 \\
\hline \multicolumn{4}{|l|}{ Diagnosis } \\
\hline COPD & $36(80.0)$ & $27(90.0)$ & 0.157 \\
\hline ILD & $4(8.9)$ & $3(10.0)$ & 0.863 \\
\hline Bronchiectasia & $10(22.2)$ & $8(26.7)$ & 0.962 \\
\hline \multicolumn{4}{|l|}{ Other pulmonary diseases with mixed } \\
\hline \multicolumn{4}{|l|}{ restrictive and obstructive pattern } \\
\hline CPFE & $\mathrm{I}(2.2)$ & $\mathrm{I}(3.3)$ & 0.893 \\
\hline Lobectomia pulmonalis & $4(8.9)$ & 0 & 0.229 \\
\hline Chest deformity & $\mathrm{I}(2.2)$ & I (6.7) & 0.320 \\
\hline Emphysema and bullae & $2(4.4)$ & $4(13.3)$ & 0.228 \\
\hline Lung destruction due to tuberculosis & $3(6.7)$ & I (3.3) & 0.286 \\
\hline Pneumoconiosis & I (2.2) & 0 & 0.452 \\
\hline Sleep-disordered breathing & $\mathrm{I}(2.2)$ & 0 & 0.356 \\
\hline Alveolar hypoventilation disorders & $2(4.4)$ & 0 & 0.452 \\
\hline \multicolumn{4}{|l|}{ Comorbidities } \\
\hline Systemic hypertension & $20(19.0)$ & $7(23.3)$ & 0.493 \\
\hline Diabetes mellitus & $4(3.9)$ & $2(6.7)$ & 0.490 \\
\hline Coronary heart disease & $4(4.8)$ & I (3.3) & 0.420 \\
\hline Malignant tumor & $I(I .0)$ & $\mathrm{I}(3.3)$ & 0.629 \\
\hline Arrhythmia & $10(9.5)$ & $2(6.7)$ & 0.460 \\
\hline Hyperlipidemia & $3(2.9)$ & $2(6.7)$ & 0.320 \\
\hline Previous cerebral infarction & $\mathrm{I}(\mathrm{I} .0)$ & 0 & 0.596 \\
\hline \multicolumn{4}{|l|}{ Pulmonary function test } \\
\hline $\mathrm{FEV}_{1} \%$ predicted & $32.8(23.7,60.4)$ & $33.0(20.0,44.3)$ & 0.201 \\
\hline FVC $\%$ predicted & $53.0(39.5,63.3)$ & $56.4(43.9,63.0)$ & 0.406 \\
\hline $\mathrm{FEV}_{1} / \mathrm{FVC} \%$ predicted & $55.2(44.5,69.0)$ & $45.0(39.7,67.5)$ & 0.067 \\
\hline RV \% predicted & $156.9(106.3,217.0)$ & I $96.4(108.1,304.0)$ & 0.237 \\
\hline TLC \% predicted & $100.5(80.8,122.1)$ & $107.2(78.3,135.4)$ & $0.46 \mathrm{I}$ \\
\hline RV/TLC \% predicted & $67.2(53.9,78.1)$ & 7I.I $(51.0,79.5)$ & 0.681 \\
\hline DLco \% predicted & $48.9(26.9,64.2)$ & $29.6(23.5,53.8)$ & 0.128 \\
\hline DLco/VA \% predicted & $50.8(27.2,72.6)$ & $35.4(23.2,66.8)$ & 0.292 \\
\hline
\end{tabular}

Note: Data shown as mean (SD) or median (quartile range).

Abbreviations: BSA, body surface area; ILD, interstitial lung disease; CPFE, combined pulmonary fibrosis and emphysema; $F_{1}$, forced expiratory volume in I second; FVC, forced vital capacity; RV, residual volume; TLC, total lung capacity; DLco, diffusing capacity for carbon monoxide; VA, alveolar volume. 
Table S3 Comparison of hemodynamics and echocardiography parameters of patients of derivation cohort vs validation cohort

\begin{tabular}{|c|c|c|c|}
\hline Variable & $\begin{array}{l}\text { Derivation cohort } \\
(n=\mid 07)\end{array}$ & $\begin{array}{l}\text { Validation cohort } \\
(n=35)\end{array}$ & $P$-value \\
\hline \multicolumn{4}{|l|}{ Hemodynamics } \\
\hline mRAP $(\mathrm{mmHg})$ & $5.0(3.0,8.0)$ & $3.0(1.0,5.0)$ & 0.001 \\
\hline $\mathrm{mPAP}(\mathrm{mmHg})$ & $36.0(29.0,48.0)$ & $35.0(28.5,42.0)$ & 0.169 \\
\hline PAWP $(\mathrm{mmHg})$ & $9.2(3.8)$ & $8.2(5.3)$ & 0.188 \\
\hline $\mathrm{CO}(\mathrm{L} / \mathrm{min})$ & $5.0(4.2,6.1)$ & $5.0(4.2,6.5)$ & 0.716 \\
\hline Cardiac index $\left(\mathrm{L} / \mathrm{min} / \mathrm{m}^{2}\right)$ & $3.3(0.9)$ & $3.2(0.8)$ & 0.820 \\
\hline PVR (Wood units) & $3.6(3.5,8.1)$ & $5.0(3.0,7.3)$ & 0.484 \\
\hline \multicolumn{4}{|l|}{ Echocardiography parameters } \\
\hline \multicolumn{4}{|l|}{ Continuous variables } \\
\hline LVEF (\%) & $70.0(64.0,77.0)$ & $70.5(62.0,77.3)$ & 0.186 \\
\hline RATD $(\mathrm{cm})$ & $4.4(3.7,5.3)$ & $4.3(3.7,4.6)$ & 0.256 \\
\hline $\operatorname{RALD}(\mathrm{cm})$ & $4.8(4.1,5.7)$ & $4.6(4.2,5.2)$ & 0.274 \\
\hline RVEDTD $(\mathrm{cm})$ & $3.9(3.3,4.5)$ & $3.7(3.5,4.2)$ & 0.581 \\
\hline RVEDSD (cm) & $6.2(5.6,6.8)$ & $6.1(5.7,6.9)$ & 0.971 \\
\hline PASP (mmHg) & $60.0(43.0,76.0)$ & $51.0(35.0,65.0)$ & 0.009 \\
\hline TAPSE $(\mathrm{cm})$ & $1.8(1.6,2.0)$ & $1.8(1.6,2.2)$ & 0.940 \\
\hline PAd $(\mathrm{cm})$ & $2.6(2.4,2.9)$ & $2.8(2.5,3.0)$ & 0.103 \\
\hline ENDSEI & $1.1(1.0,1.3)$ & I.I (I.0, I.3) & 0.338 \\
\hline \multicolumn{4}{|l|}{ Categorical variables } \\
\hline $\mathrm{RH}$ enlargement* - yes & $8 \mathrm{l}(75.7 \%)$ & $22(73.3 \%)$ & 0.792 \\
\hline PA dilation - yes & 48 (44.9\%) & $17(56.7 \%)$ & 0.094 \\
\hline ENDSEI - yes & $60(56.1 \%)$ & $15(50.0 \%)$ & 0.556 \\
\hline PASP - yes & $93(86.9 \%)$ & $17(56.7 \%)$ & $<0.001$ \\
\hline
\end{tabular}

Notes: Data shown as mean (SD), median (25th, 75th percentiles) or $\mathrm{n}(\%)$. *Include right atrium and right ventricle enlargement.

Abbreviations: mRAP, mean right atrium pressure; mPAP, mean pulmonary artery pressure; PAWP, pulmonary artery wedge pressure; CO, cardiac output; PVR, pulmonary vascular resistance; LVEF, left ventricular ejection fraction; RATD, right atrial transverse dimension; RALD, right atrial longitudinal dimension; RVEDTD, right ventricular end-diastolic transverse dimension; RVEDSD, right ventricular end-diastolic dimension; PASP, pulmonary artery systolic pressure; TAPSE, tricuspid annular plane systolic excursion; PAd, pulmonary arterial diameter; ENDSEl, end-systolic eccentricity index; RH, right heart; PA, pulmonary artery.

\section{Publish your work in this journal}

The International Journal of COPD is an international, peer-reviewed journal of therapeutics and pharmacology focusing on concise rapid reporting of clinical studies and reviews in COPD. Special focus is given to the pathophysiological processes underlying the disease, intervention programs, patient focused education, and self management protocols.

\section{Dovepress}

This journal is indexed on PubMed Central, MedLine and CAS. The manuscript management system is completely online and includes a very quick and fair peer-review system, which is all easy to use. Visit http://www.dovepress.com/testimonials.php to read real quotes from published authors. 